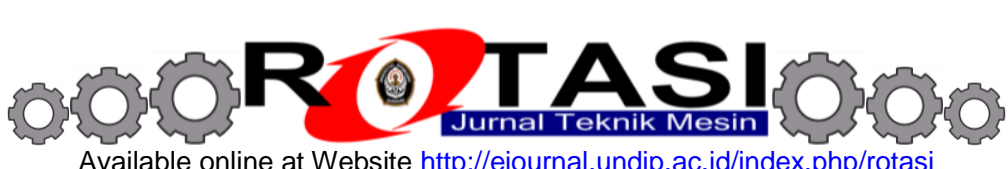

Available online at Website http://ejournal.undip.ac.id/index.php/rotasi

\title{
ANALISIS DISTRIBUSI ALIRAN SPRINKLE TEKANAN RENDAH
}

\author{
Susilo Adi Widyanto \\ Jurusan Teknik Mesin, Fakultas Teknik, Universitas Diponegoro \\ Jl. Prof. Sudharto, SH, Tembalang, Semarang 50275 \\ E-mail: susilo70@yahoo.com
}

\begin{abstract}
ABSTRAK
Kebutuhan pangan terus meningkat seiring dengan pertumbuhan jumlah penduduk, tetapi pada sisi lainnya daya dukung alam termasuk luas lahan pertanian terus menurun dari tahun ke tahun, sedangkan perubahan iklim menunjukkan pola yang semakin ekstrim. Penerapan teknik irigasi yang mengacu pada analisis kondisi lingkungan perlu dipertimbangkan untuk mengatasi persoalan turunnya produktivitas hasil pertanian. Penggunaan sprinkle sebagai mekanisme pendistribusi aliran air irigasi telah lazim digunakan. Namun permasalahan distribusi aliran merupakan aspek penting yang harus diselesaikan agar dapat mendukung pengotomasian sistem irigasi. Penelitian dilakukan dengan menggunakan empat jenis sprinkle rotari. Setiap sprinkle diuji distribusi alirannya dengan metode mengukuran massa air sebagai fungsi radius posisi sprinkle. Pengujian dilakukan dengan memvariasikan ketinggian air suplai dalam kurun waktu 3 menit. Data karakteristik distribusi aliran sebagai fungsi dari jenis sprinkle dan ketinggian air suplai yang diperoleh digunakan sebagai dasar desain ulang salah satu jenis sprinkle yang akan dikembangkan untuk mendukung sistem irigasi terotomasi. Hasil penelitian menunjukkan bahwa sprinkle yang dijual dipasaran hampir semuanya tidak memenuhi karakteristik distribusi aliran yang baik pada luasan pembasahan. Perbaikan desain secara umum dapat dilakukan dengan mengatur posisi lubang aliran keluaran yang disesuaikan dengan daerah pembasahan yang dituju serta mengubah diamater lubang efektif yang dikaitkan dengan luasan daerah pembasahan dan pertimbangan distribusi tekanan dalam konstruksi sprinkle.
\end{abstract}

Kata kunci: Sprinkle, sistem irigasi, pangan

\section{PENDAHULUAN}

Pangan merupakan kebutuhan dasar bagi kehidupan sehingga ketersediannya mutlak diperlukan sepanjang masa. Kebutuhan akan pangan juga terus meningkat seiring dengan pertumbuhan jumlah penduduk. Namun pada sisi yang lain, daya dukung alam semakin menurun akibat eksploitasi yang semakin tidak terkendali. Lahan pertanian yang terus menyusut, berdasarkan data dari Badan Pusat Statistik (BPS) pada tahun 2010 saja penyusutan lahan panen padi nasional mencapai 12,63 ribu hektare atau sekitar 0,1\% total luas lahan [1]. Perubahan iklim menunjukkan pola yang semakin ekstrim, sehingga ketersediaan sumber daya air terus menurun dan menjadi langka pada saat musim kemarau.

Selain diperlukan perbaikan tata aturan tentang pengubahan fungsi lahan, tindakan nyata untuk meningkatkan kualitas dan produktivitas produk pertanian mendesak diperlukan. Untuk mengatasi persoalan tersebut, penerapan sistem otomasi pertanian yang diawali dengan sistem irigasi terotomasi merupakan salah satu usaha yang sangat penting untuk dipertimbangkan.

Salah satu metode irigasi terotomasi yang banyak digunakan adalah sistem irigasi sprinkle. Irigasi sprinkle pada dasarnya merupakan metode irigasi dengan penyemprotan air pada permukaan tanah sebagai bentuk hujan buatan. Untuk menghasilkan pola presipitasi, air bertekanan diinjeksikan melalui nosel yang disebut dengan sprinkle. Sistem irgasi sprinkle telah dikembangkan dalam berbagai desain dan kapasitas. Terdapat dua kategori sprinkle berdasarkan dimensi pembasahan, yaitu sprinkle besar dan kecil. Penggolongan tersebut didasarkan pada radius pembasahan yang dihasilkan. Untuk radius pembasahan kecil (sprinkle kecil) dihasilkan oleh tekanan air yang rendah. Laju presipitasi yang dihasilkan juga relative ringan sehingga kemungkinan erosi tanah yang dihasilkan dapat diabaikan. Sistem irigasi dengan sprinkle kecil digunakan untuk penerapan irigasi lahan sempit seperti pada skala rumah tangga [2].

Dalam implementasinya, perencanaan sistem irigasi terotomasi dengan menggunakan sprinkle harus mempertimbangkan banyaknya air yang tersedia untuk sistem irigasi tersebut. Penggunaan sumber air tertentu menentukan tahapan desain yang diperlukan. Residential Sprinkler System Design Handbook menguraikan, dari data tekanan air akan ditentukan jenis sprinkle yang akan digunakan, sedangkan kapasitas sumber air yang tersedia digunakan untuk menentukan dimensi sprinkle [3].

Pengaplikasian sistem sprinkle dalam metode irigasi terotomasi harus memenuhi kriteria distribusi aliran yang baik. Secara umum, distribusi air dengan sistem irigasi sprinkler dibagi dalam dua tahapan distribusi, yaitu distribusi dari nozel sprinkle ke tanah atau permukaan tanaman dan distribusi dalam profil tanah dari permukaan tanah. Air didistribusikan ke permukaan tanah atau permukaan tanaman secara mekanis. Penyimpangan dari pola distribusi terjadi akibat kecepatan dan arah angin yang terjadi secara acak [4]. Observasi distribusi sprinkle karena pengaruh jenis sprinkle telah dilakukan oleh Makki dkk. [5]. Hasil penelitiann mereka mengungkapkan bahwa nosel kuningan 
dengan kepala ganda memberikan distribusi aliran yang lebih baik untuk semua konfigurasi sprinkle. Sedangkan pada kecepatan angin rendah $<2,0 \mathrm{ml}$ ) dan konfigurasi yang sempit, nosel sprinkle tunggal dari bahan plastik memberikan nilai yang lebih baik dari sprinkle kuningan maupun plastik dengan kepala ganda. Pengkorelasian distribusi aliran sprinkle dengan kerugian evaporasi telah diteliti oleh Koo and Reese [6]. Mereka menyebutkan bahwa koefisien distribusi yang lebih tinggi diperoleh pada irigasi malam hari untuk seluruh sistem irigasi yang diobservasi. Distribusi air juga dipengaruhi oleh jarak sprinkle, dimana jarak yang lebih dekat menghasilkan distribusi air yang lebih seragam. Kerugian evaporasi lebih tinggi terjadi pada siang hari, yaitu sekitar 11 sampai $19 \%$ untuk sprinkle tetap dan 0 sampai $7 \%$ untuk gun sprinkle.

Penelitian ini mengusulkan metode pengukuran distribusi alliran untuk berbegai jenis sprinkle yang ada di pasaran Hasil pengujian distribusi aliran tersebut akan digunakan sebagai dasar modifikasi salah satu jenis sprinkle agar memiliki distribusi aliran yang lebih baik.

\section{METODOLOGI}

Untuk memperoleh sprinkle dengan distribusi aliran air yang baik, penelitian akan dilaksanakan mengikuti matodologi sebagai berikut:

\subsection{Penentuan Jenis Sprinkle}

Berbagai jenis sprinkle telah umum dipasarkan untuk sistem irigasi pertamanan maupun tujuan khusus dalam skala rumah tangga. Tujuan utama penerapan sprinkle adalah untuk mendistribusikan air irigasi sekalipun aspek distribusi yang baik belum dipertimbangkan sepenuhnya. Penelitian ini menggunakan jenis-jenis sprinkle tekanan rendah dimana cara kerjanya untuk pendistribusian air irigasi didasarkan atas gaya gravitasi yang digunakan untuk memutar sejumlah nosel. Sprinkle yang akan diuji seperti ditunjukkan dalam Gambar 1a, 1b, dan 1c.

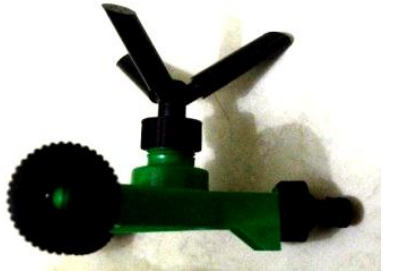

(a)

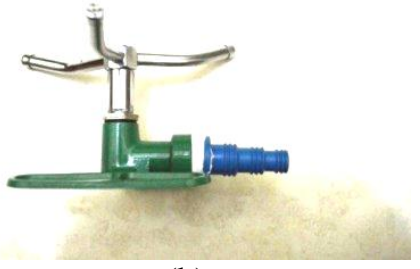

(b)

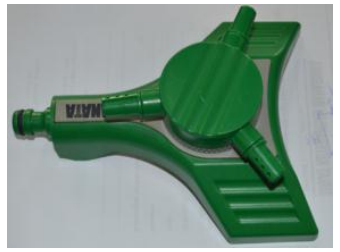

(c)

Gambar 1. Jenis sprinkle yang diuji karakteristik distribusi alirannya, a. Sprinkle 1, b. Sprinkle 2, c. Sprinkle 3.

\subsection{Metode Pengujian Karakteristik Distribusi Aliran Sprinkle}

Pengujian karakteristik distribusi aliran tiap jenis sprinkle dilakukan dengan mengukur masa air yang dialirkan oleh sprinkle sebagai fungsi posisi radiusnya. Massa piringan yang akan digunakan telah ditimbang sebelumnya sehingga massa alir merupakan pengurangan massa total dengan massa piringan. Pengukuran dilaksanakan selama 3 menit dengan memvariasikan ketinggian sistem reservoir yang menyatakan energi potensial air suplai ke sistem sprinkle. Ketinggian yang dipilih adalah: 220, 265 dan $330 \mathrm{~cm}$. Set-up pengujian karakteristik distribusi aliran sprinkle dan Metode pengujiannya seperti ditunjukkan dalam Gambar 2 dan 3.

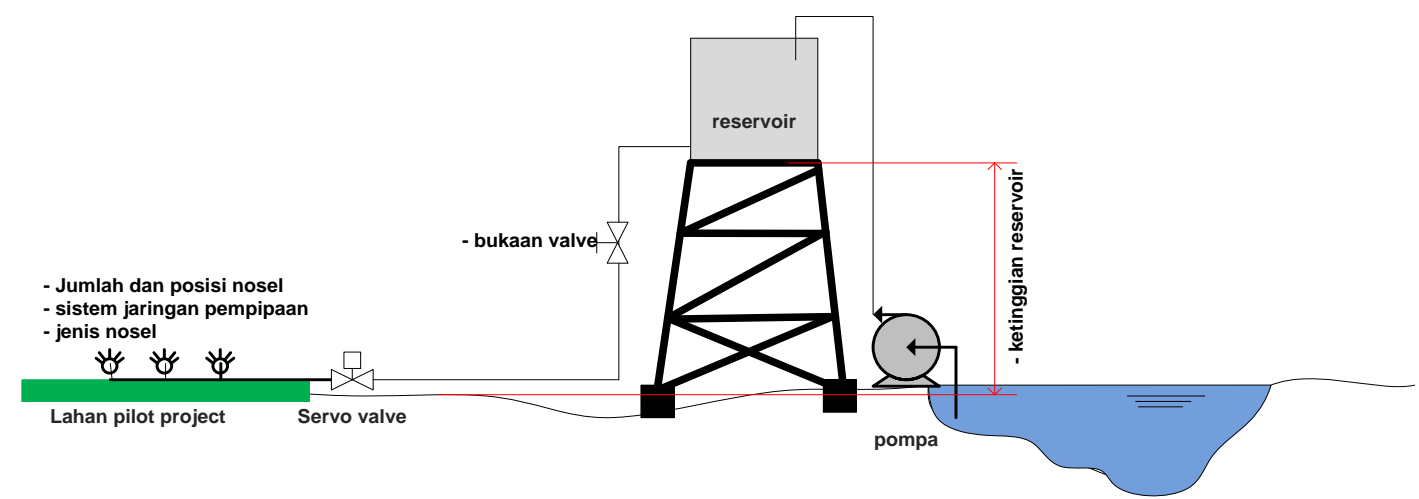

Gambar 2. Set-up pengujian karakteristik distribusi aliran sprinkle. 


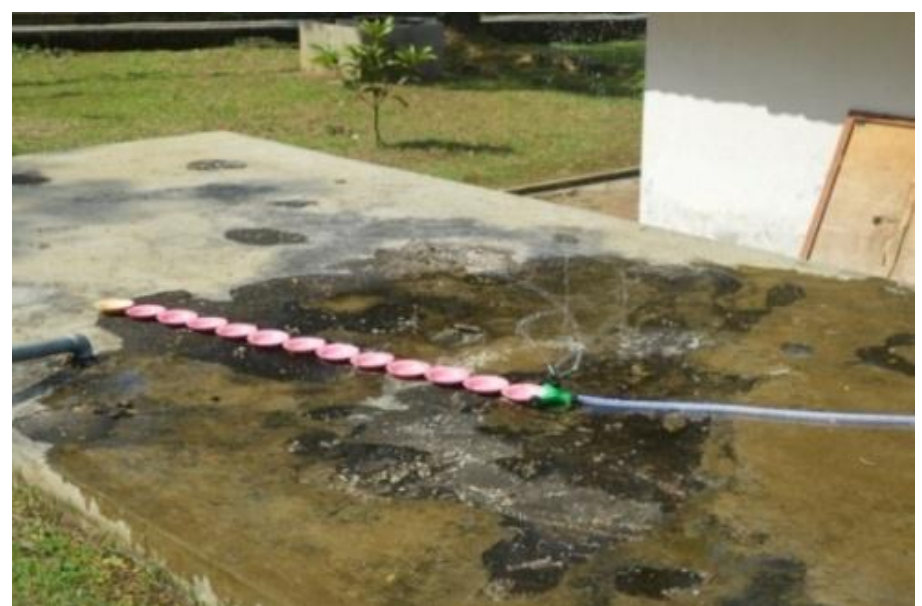

Gambar 3. Metode pengujian karakteristi distribusi aliran sprinkle.

\subsection{Modifikasi Sprinkle}

Untuk dapat menganalisis cara kerja setiap jenis sprinkle, tiap sprinkle tersebut digambar ulang geometrinya sehingga analisis aliran dapat dilakukan. Dari hasil analisis tersebut dampak tiap parameter geometri dapat ditentukan. Kondisi tersebut yang akan digunakan dalam proses desain ulang sprinkle. Beberapa konsep desain yang dapat digunakan untuk memperbaiki karakteristik distribusi aliran antara lain adalah penerapan mekanisme pengarah aliran, pengaturan gerakan dengan memanfaatkan energi kinetik aliran dan penggunaan mekanisme yang memanfaatkan tekanan balik akibat aliran air irigasi. Konsep modifikasi sprinkle yang dilakukan dalam penelitian ditunjukkan dalam Gambar 4 .

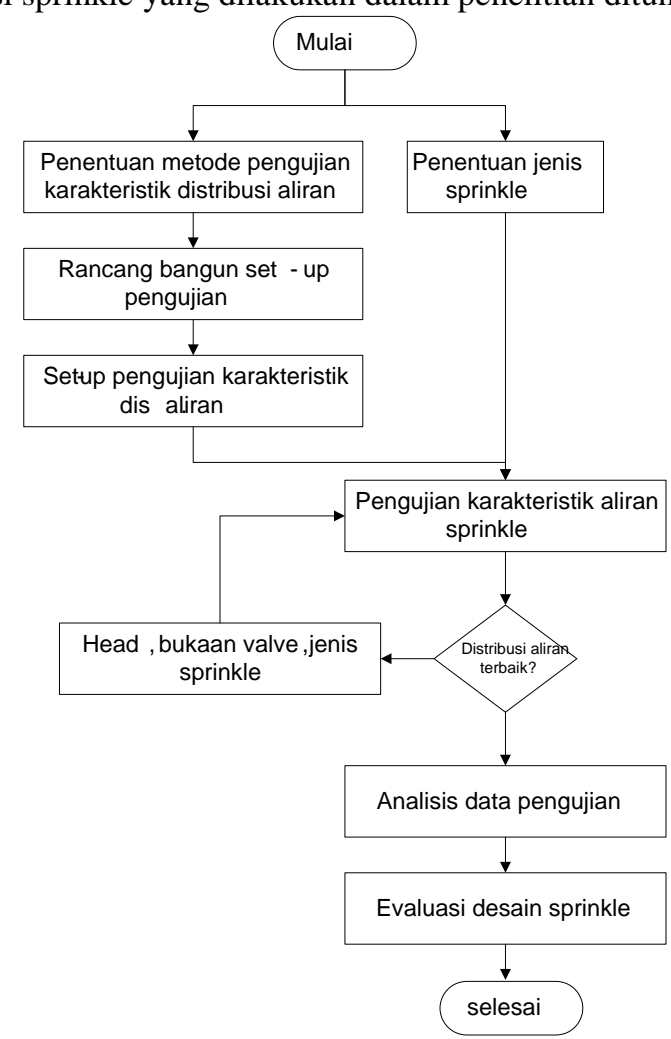

Gambar 4. Konsep modifikasi sprinkle.

\section{HASIL DAN PEMBAHASAN}

Syarat utama suatu mekanisme sprinkle dapat diterapkan sistem irigasi terotomasi adalah dihasilkannya distribusi aliran air yang baik. Karena alasan inilah pengujian distribusi aliran sprinkle dilakukan. Pengujian distribusi aliran dilakukan dengan memvariasikan ketinggian air suplai (head) dan bukaan katup air suplai. Hasil pengolahan data pengujian akan digunakan untuk menentukan head dan kapasitas aliran optimal serta jenis sprinkle terbaik yang akan diaplikasikan dalam sistem irigasi cerdas. Dari hasil pengujian ketiga jenis sprinkle diperoleh karakteristik distribusi aliran tiap sprinkle yang dinyatakan dalam bentuk grafik sebagai berikut:

\subsection{Hasil Pengujian Distribusi Aliran Berbagai Jenis Sprinkle}


Dari ketiga jenis sprinkle yang diuji pada head $265 \mathrm{~cm}$, sprinkle 2 memiliki karakteristik distribusi aliran yang paling rendah. Gambar 5 menunjukkan bahwa pada radius sampai dengan $100 \mathrm{~cm}$, lahan tidak terbasahi sedangkan pembasahan maksimum terjadi di lokasi yang beradius sekitar $150 \mathrm{~cm}$ dari pusat sprinkle. Dengan menggunakan jenis sprinkle 3, hampir seluruh lokasi yang beradius kurang dari $150 \mathrm{~cm}$ terbasahi, tetapi pembasahan terbesar justru terjadi pada lokasi yang paling dekat dengan sprinkle.

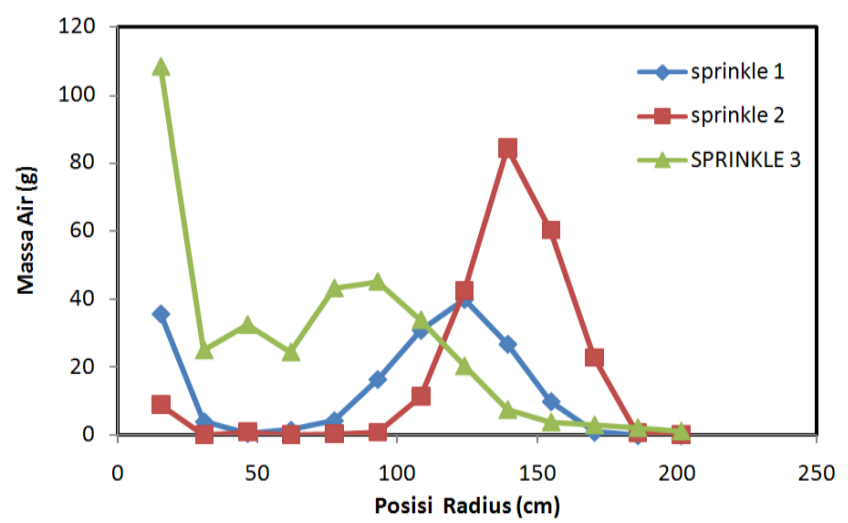

Gambar 5. Hasil pengujian karakteristik distribusi aliran tiga jenis sprinkle (head $265 \mathrm{~cm}$, waktu pengukuran 3 menit).

\subsection{Karakteristik Distribusi Aliran Berbagai Jenis Sprinkle Dengan Variasi Head}

Variasi harga head (ketinggian air masuk) terbukti tidak mempengaruhi karakteristik distribusi aliran sprinkle 1 maupun sprinkle 2 seperti ditunjukkan dalam Gambar 6 dan 7. Namun secara umum head berpengaruh pada posisi pembasahan maksimumnya. Pada sprinkle 2, lokasi pembasahan maksimum akan bergeser mejauhi sprinkle bila head ditingkatkan.

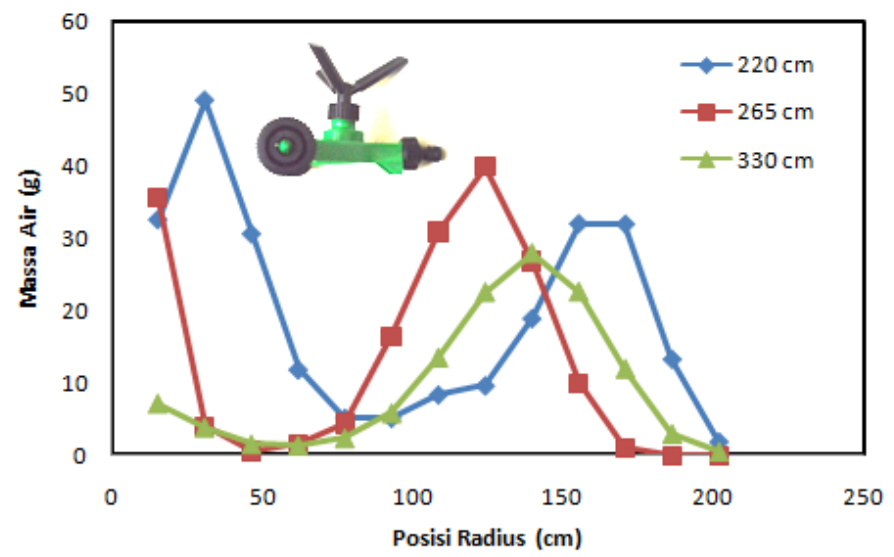

Gambar 6. Hasil pengujian karakteristik distribusi aliran sprinkle 1 pada variasi head (waktu pengukuran 3 menit).

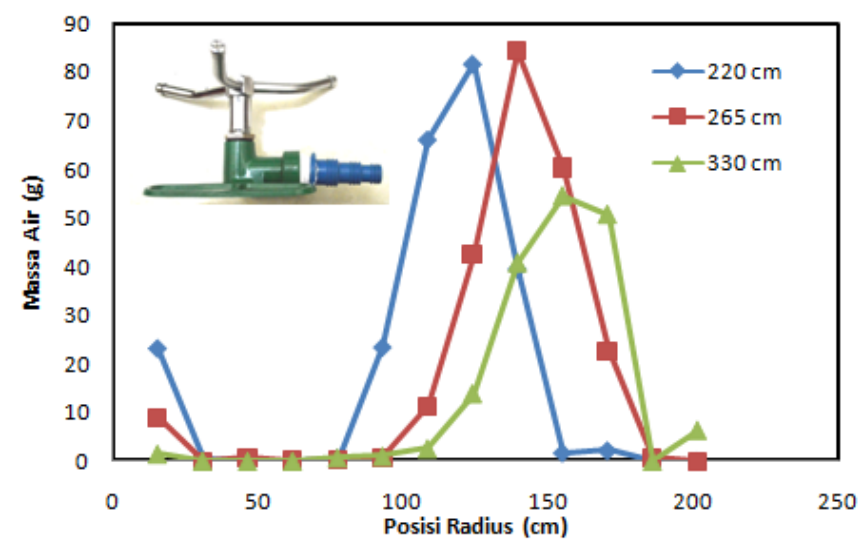

Gambar 7. Hasil pengujian karakteristik distribusi aliran sprinkle 2 pada variasi head (waktu pengukuran 3 menit).

\subsection{Karakteristik Distribusi Aliran Berbagai Jenis Sprinkle Dengan Kapasitas Aliran (bukaan valve)}


Peningkatan kapasitas aliran pada sprinkle 1 ternyata tidak mengubah pola distribusi pembasahan seperti ditunjukkan dalam Gambar 8. namun secara umum peningkatan kapasitas aliran air hanya menggeser daerah pembasahan pada fungsi radiusnya. Dibandingkan dengan dua jenis sprinkle lainnya, distribusi pembasahan yang dihasilkan oleh sprinkle ini paling baik, hal tersebut ditunjukkan oleh munculnya dua daerah pembasahan yang tinggi yang tidak dijumpai pada pembasahan sprinkle jenis lain.

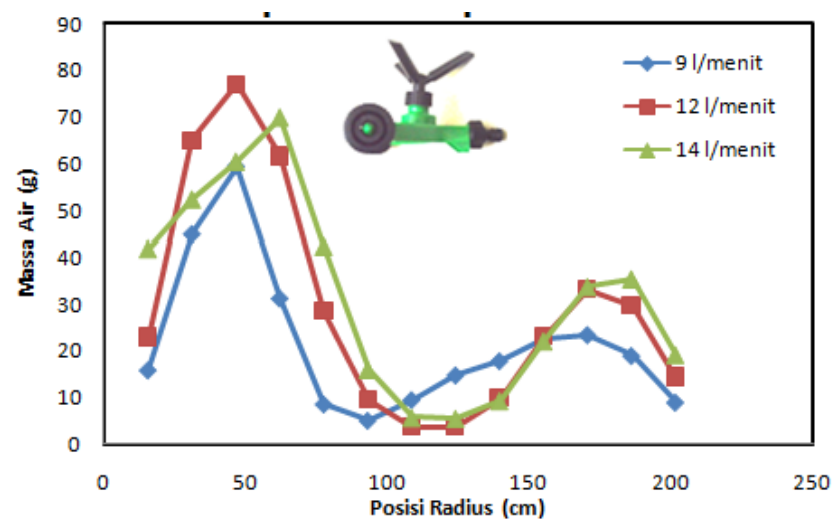

Gambar 8. Pola distribusi pembasahan sprinkle jenis 1 pada variasi bukaan katup.

Peningkatan kapasitas aliran air pada sprinkle 2 memiliki kecenderungan yang sama dengan peningkatan head aliran air masuk, yaitu menggeser daerah pembasahan menjauhi sprinkle. Peningkatan kapasitas aliran tidak mengubah pola distribusi pembasahan seperti ditunjukkan dalam Gambar 9.

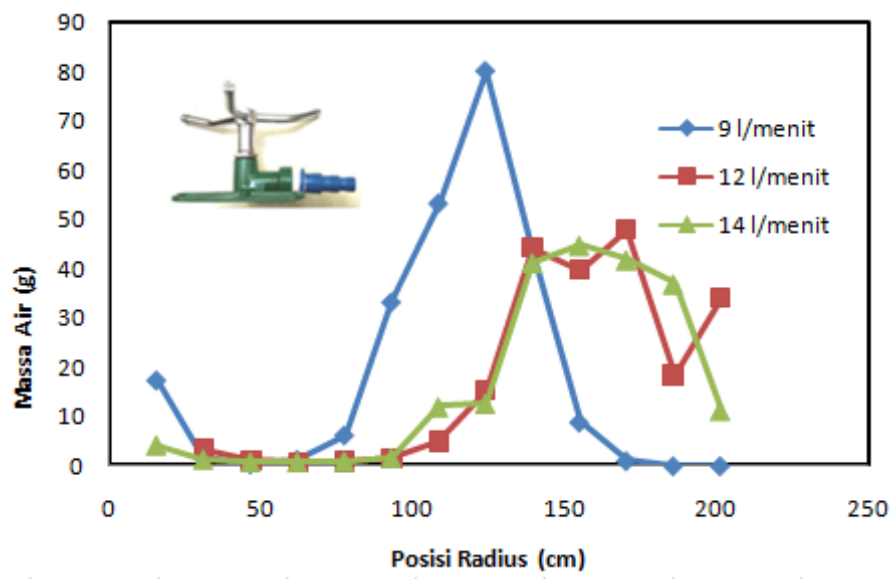

Gambar 9. Pengaruh variasi kapasitas aliran air masuk pada pola distribusi pembasahan sprinkle jenis 2.

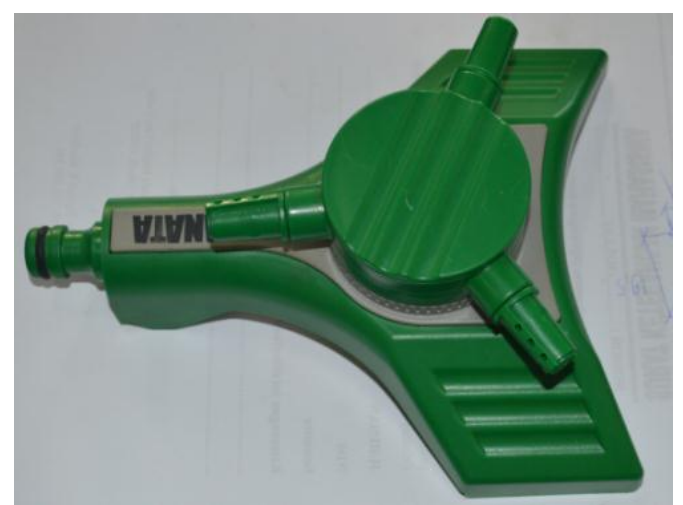

Gambar 10. Sprinkle jenis 4 dengan tiga jalur aliran yang dapat diatur orientasinya.

Sprinkle 3 (Gambar 10) merupakan sprinkle jenis baru dimana orientasi lubang dapat diatur untuk memperoleh distribusi aliran yang baik. Namun dari desain yang ada, lubang sprinkle terlalu besar dan formasi sudut yang tidak optimal. Dari desain yang ada, sprinkle 3 memiliki kelemahan antara lain: kapasitas aliran terlalu besar bahkan dengan sprinkle 3 pun kapasitas alirannya lebih tinggi (Gambar 11). Hal ini mempersulit pengaturan kelembaban tanah bila diaplikasikan dalam sistem terotomasi. Kelamahan lainnya adalah radius aliran yang relatif kecil dengan kondisi yang 
tidak merata dimana kapasitas aliran semakin mengecil sebanding dengan radiusnya. Kesalahan dalam penentuan orientasi lubang untuk tiap jalur aliran justru dapat menyebabkan ketidakstabilan (berhenti) putaran sprinkle. Didasarkan pada kondisi tersebut dapatlah dikatakan bahwa fleksibitas yang dibuat untuk tiap jalur alirannya tidak efektif dalam aplikasi pengaturan distribusi aliran sprinkle.

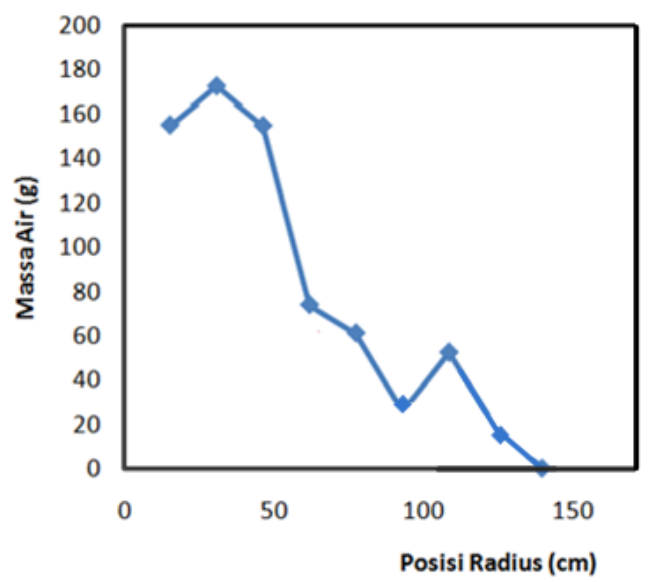

Gambar 11. Pola distribusi spinkle 3 (panjang slang $10 \mathrm{~m}$ ).

\subsection{Modifikasi Sprinkle untuk Memperbaiki Pola Distribusi Aliran}

Syarat utama agar sprinkle dapat diaplikasikan dalam sistem terotomasi adalah pola distribusi aliran yang dihasilkan harus baik sehingga diseluruh area yang dikendalikan memiliki kondisi yang seragam dalam pengukuran kelembaban tanah dengan pengendalian air irigasi. Selain itu kapasitas aliran yang dihasilkan harus relatif kecil sehingga pengendalian jumlah air irigasi dapat dilakukan dengan akurat. Dari keempat jenis sprinkle menunjukkan bahwa tidak satu pun memiliki pola distribusi aliran yang baik sehingga perlu dimodifikasi.

Modifikasi dengan mudah dilakukan untuk jenis sprinkel 1 dan sprinkle 2, dimana kondisi alirannya sedang dan lebih kecil dibandingkan sprinkle 3. Sprinkle 1 memiliki dua daerah aliran sehingga perbaikan cenderung dilakukan untuk menurunkan daerah aliran satu dan dua untuk mengisi celah aliran di bagian tengahnya (Gambar 9). Sedangkan sprinkle 2, daerah aliran terlalu jauh dari sprinklenya, sehingga daerah yang dekat dengan sprinkle tersebut relatif kurang.

Konstruksi sprinkle 2 seperti ditunjukkan dalam Gambar 12 berikut ini yang merupakan hasil penggambaran dengan perangkat CAD.
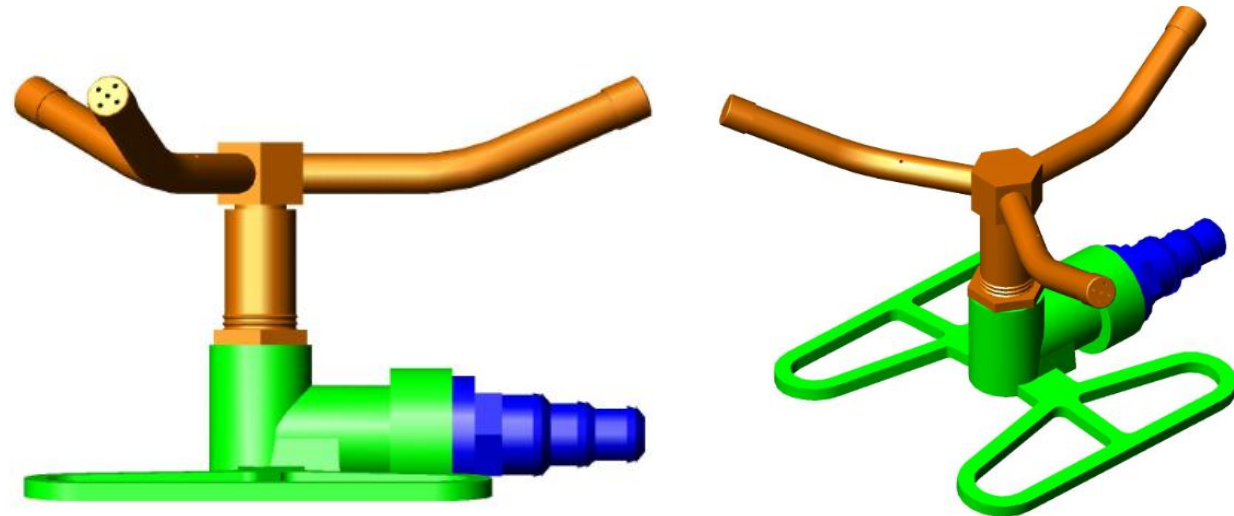

Gambar 12. Gambar CAD sprinkle 2.

Modifikasi sprinkle 2 dilakukan dengan mengatur arah aliran yang berbeda untuk ketiga jalur keluarannya dan mengubah posisi lubang jalur keluaran bagian tengah. Pengaturan arah aliran tersebut dilakukan dengan memutar arah belokan jalur keluaran seperti ditunjukkan dalam Gambar 13. Dari gambar tersebut terlihat bahwa saluran keluaran tiap jalurnya terdiri dari saluran bantu yang berada pada permukaan pipa keluaran dan saluran utama yang terdiri dari 5 lubang pada ujung penampang permukaan saluran keluaran. Saluran bantu bertujuan untuk mendistribusikan air pada daerah tengah dan pusat, namun pada kenyataannya arah aliran keatas tersebut distribusinya dipengaruhi oleh aliran angin dan tidak proporsional dengan jumlah air yang disalurkan melalui saluran utama. 


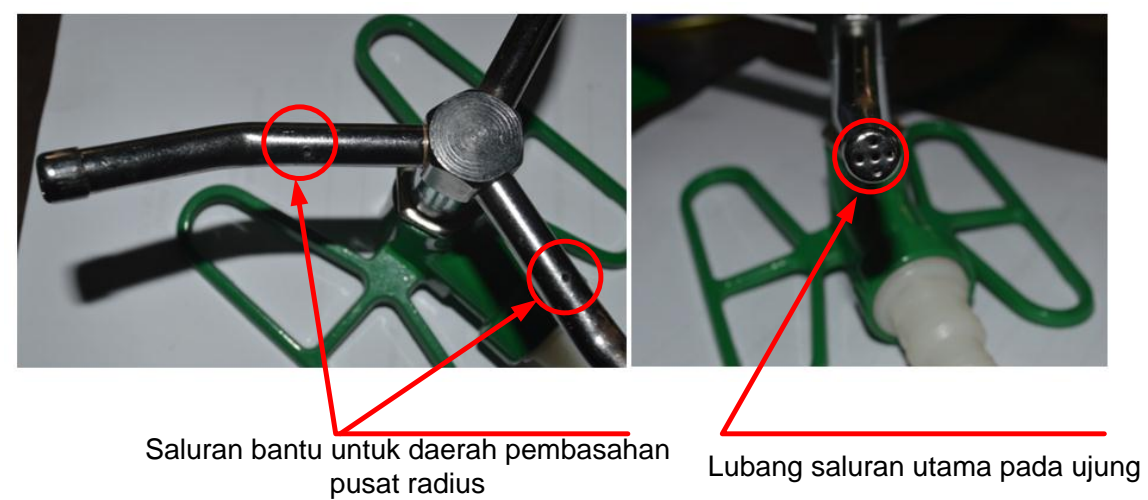

Gambar 13. a) Saluran bantu untuk mendistribusikan air di daerah tengah dan pusat, b) Saluran utama yang berada pada ujung penampang saluran keluaran.

Dari kurva distribusi disimpulkan bahwa modifikasi ditujukan untuk memberikan aliran pada daerah pusat dan tengah dari daerah distribusi yang dihasilkan oleh sprinkle awal (kurva warna biru, Gambar 14). Modifikasi pertama dilakukan dengan memperbesar lubang saluran bantu. Hasil pengujian menunjukkan bahwa kondisi distribusi diperbaiki secara signifikan. Justru pada daerah pusat terjadi kelebihan distribusi aliran, sedangkan sebaliknya daerah luar menjadi mininal (kurva warna hijau, Gambar 14). Hal ini menunjukkan bahwa diamater saluran bantu efektif untuk diubah, namun perlu dilakukan optimasi diamater lubangnya.

Modifikasi kedua dilakukan dengan mengatur jumlah saluran utama berserta dengan orientasinya sehingga distribusi pada seluruh daerah pembasahan dapat diefektifkan. Jumlah lubang saluran ditentukan berdasarkan pertimbangan luasan pembasahan, dimana untuk radius kecil, luas daerah pembasahan juga kecil sehingga jumlah lubang sedikit. Sudut saluran pertama diarahkan untuk memberikan aliran pada daerah pusat, jumlha lubang dikurangi menjadi 3, sudut saluran kedua diarahkan pada daerah tengah dengan lubang saluran 4 lubang sedangkan sudut saluran ketiga diarahkan untuk pemberinan aliran pada daerah terluar dengan 5 lubang.

Hasil pengujian menunjukkan bahwa daerah pembasahan pusat terkurangi, pembasahan maksimum terjadi pada daerah tengah (kurva warna merah, Gambar 14). Hasil ini mengindikasikan bahwa diamater lubang saluran perlu diperbaiki terutama pada daerah pembasahan tengah dengan memperkecil diameternya, sedangkan diamater lubang saluran utama untuk daerah pembasahan luar perlu dilakukan perbesaran.

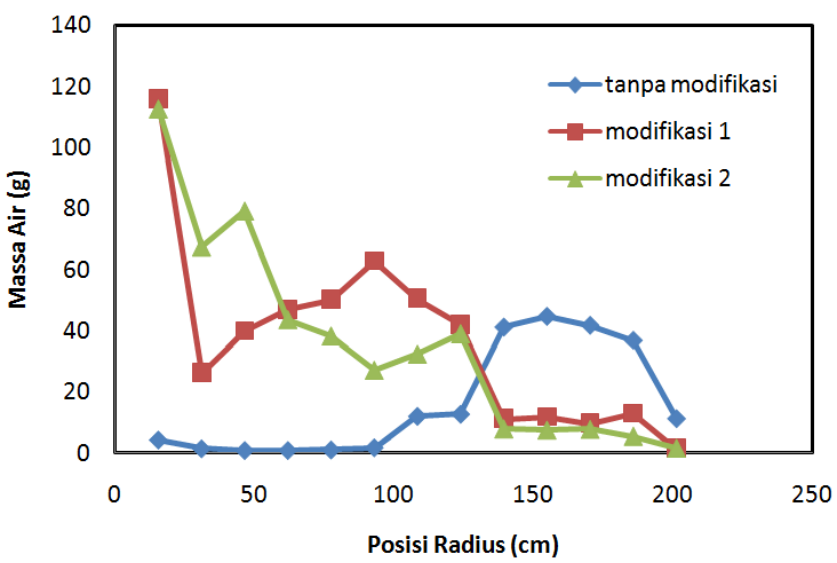

Gambar 14. Karakteristik distribusi aliran sprinkle 2.

\section{KESIMPULAN}

Dari berbagai bentuk sprinkle tekanan rendah yang ada dipasaran tidak satupun yang memiliki distribusi aliran yang baik. Kondisi tersebut terutama disebabkan dalam desainnya tidak mempertimbangkan analisis distribusi aliran untuk segmen daerah pembasahan sebagai fungsi radiusnya. Dari hasil pengujian didapatkan bahwa energi potensial (tekanan) masuk fluida maupun kapasitas alirannya tidak mengubah pola distribusi aliran sprinkle tersebut.

\section{PUSTAKA}

[1] Media Indonesia, 2 Juli 2010

[2] Anonim., 2000, "Appropriate irrigation technology for smallholder farmers", International Development Enterprises (IDE), Nepal- Kathmandu

[3] Anonim., nd, "Residential Sprinkler System Design Handbook", Hunter Industries Incorporated

[4] Pair C. H., 1968, "Water Distribution Under Sprinkler Irrigation”, Transactions of the ASAE., 11(5). 648-650. 
[5] Makki E. K., Ali O. O., and Mohamed A. E., 2011, "Evaluation of Uniformity Coefficient and Water Distribution Efficiency of Some Impact Sprinklers in Shambat, Sudan”, J. Agric. Sci. 19(2). 161-177.

[6] Koo R. C. J., and Reese R. L., nd ,'Water Distribution And Evaporational Loss From Sprinkler Irrigation In Citrus", AS Agricultural Research and Education Center, Lake Alfred 